\title{
Surgical Management of Intestinal Obstruction due to Pebbles in a Labrador Dog
}

\section{G. Kamalakar*, Thara Singh D. Lamani, L. Suresh, K. Saigunaranjan and B.N. Nagaraja}

Department of Veterinary Surgery and Radiology, Veterinary College, Hebbal, Bengaluru.

*Corresponding author: Ph.D. Scholar, E-mail drkamal_vet@yahoo.co.in; drkamallvet@gmail.com

Journal of Livestock Science (ISSN online 2277-6214) 10:19-21

Received on 17/9/2018; Accepted on 2/2/2018

doi. 10.33259/JLivestSci.2019.19-21

\begin{abstract}
An adult Labrador dog presented with signs of prolonged anorexia, vomition, dehydration, not passing stools and weakness. It was suspected as intestinal obstruction on abdominal palpation and history. The dog was stabilized with fluid therapy and an emergency laparo-enterotomy was performed and retrieved few pebbles. With good pre and post-operative treatment, the animal recovered uneventfully.
\end{abstract}

Keywords: Labrador dog; intestinal foreign body; laparo-enterotomy; pebbles. 


\section{Introduction}

In dogs, preponderance of intestinal obstruction was very high due to their indiscriminate feeding nature (Ellison, 1990). The obstructing foreign bodies may be linear (Prasad et al., 2010) or discrete (Hayes, 2009; Raghunath et al., 2016). Various other causes of intestinal obstruction reported to be were resultant of tumours, hypertrophy, gastric dilatation, volvulus, intussusception or foreign bodies (Atray et al., 2012). The indigestible foreign bodies may lead to complete or partial obstruction. Severe electrolyte imbalance is seen in such cases due to vomitions and anorexia. Always these cases have to be attended by early surgical intervention (Crha, 2008). In the present report, we describe surgical management of complete intestinal obstruction due to pebbles in a Labrador dog.

\section{Case History and Clinical Observations}

An 8 year old Labrador retriever bitch was presented to Dept. of Veterinary Surgery \& Radiology, Veterinary College, Hebbal, Bengaluru with signs of severe chronic vomitions, anorexia, not passing stools since 3 days, dehydration, slightly distended abdomen and profound weakness since 10 days. Clinically it was dull, dehydrated, normothermic $\left(101.2{ }^{\circ} \mathrm{F}\right)$, bradycardiac (60 beats/ min) and bradypnoeic (38 breaths/ min). Abdominal palpation revealed some hard masses in caudal abdomen. Hematological (RBC -4.8 lakhs/ cmm, $\mathrm{WBC}-11,500 / \mathrm{cmm}, \mathrm{Hb}-12 \%$ ) and biochemical parameters (creatinine $-0.8 \mathrm{mg} / \mathrm{dL}, \mathrm{ALT}-45 \mathrm{IU} / \mathrm{L}, \mathrm{AST}-$ $12 \mathrm{IU} / \mathrm{L})$ were within normal range. An emergency exploratory laparotomy was planned and executed.

\section{Treatment and Discussion}

Preoperatively the dog was stabilized with Dexamethasone @ $1 \mathrm{mg} / \mathrm{kg}$, RL $500 \mathrm{ml}$, DNS $500 \mathrm{ml}$ and Ceftriaxone @ 20 mg/kg I/V. Preanaesthetized with atropine @ 0.04 mg/kg S/C and xylazine @ 1 mg/ kg I/M. General anaesthesia induced and maintained with thiopentone sodium @ $12.5 \mathrm{mg} / \mathrm{kg} \mathrm{I} / \mathrm{V}$. After asceptic precaution, mid ventral laparo-enterotomy was performed. Completely dilated and congested jejuno-ileal loops were exteriorized (Fig 1) and actual obstruction was found to be at ileo-caeco-colic junction. Few small pebbles were found entrapped at this area and were removed (Fig 2) by enterotomy at anti mesenteric end over ileum. 4 pebbles were found at that junction and 6 more in various distances from ileo-caeco-colic junction. Size of pebbles varied from $1-2 \mathrm{~cm}$. Whole anterior loops were distended with gas and at few places the serosa was perforated. The enterotomy wound was irrigated with NS and then sutured in single layer cushing's pattern using chromic catgut no. 2-0 (Fig 3). Whole viscera was irrigated with NS and replaced in to abdomen. Linea alba was closed using vicryl no. 1 in simple interrupted manner followed by sub cutaneous and cutaneous sutures routinely. Post operatively the dog was administered with RL $500 \mathrm{ml}$ and metronidazole $100 \mathrm{ml} \mathrm{I/V}$. In spite of extreme measures, the dog succumbed to death on next day owing to delay in presentation.

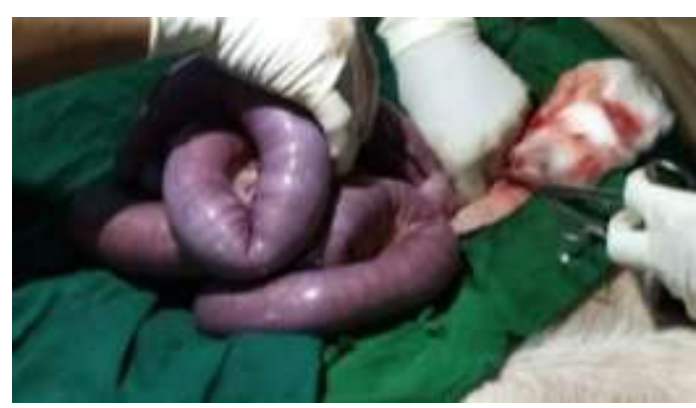

Fig 1: Photograph showing distended and inflammed intestines 


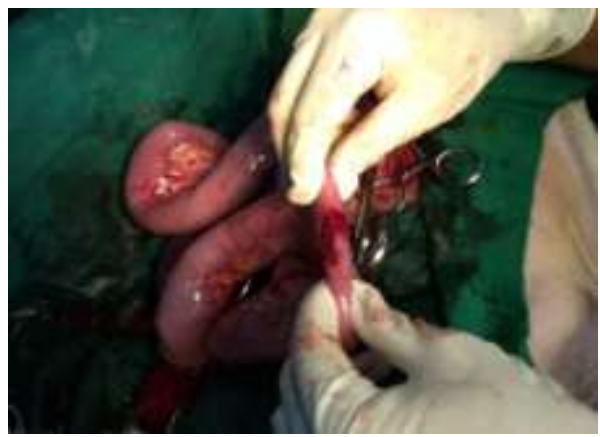

Fig 2: Photograph showing sutured enterotomy incision

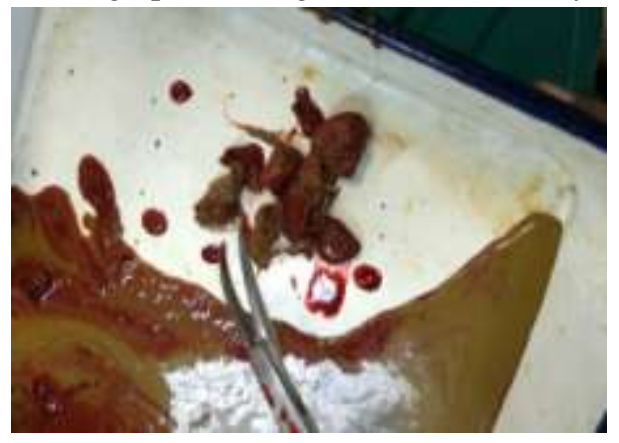

Fig 3: Photograph showing retrieved pebbles through enterotomy

Foreign bodies become impacted in the gastrointestinal tract at both normal and pathologic points of narrowing (Tams and Seim, 2013). In the present case, the dog was presented after 3 days with the signs of vomition, anorexia, dullness, gradual weakness and dyschezia as were also reported by Prasad et al. (2010), Raghunath et al. (2016) and Muhammad et al. (2014). Abdominal palpation could give an idea of suspected obstruction. Intestinal obstruction was due to few small pebbles. Various authors reported obstructions due to trichobezoirs (Albernaz, et al., 2017), sand particles (Muhammad et al., 2014), saree piece (Prasad et al., 2010), stones (Hayes, 2009), corn cob (Raghunath et al., 2016), etc. The intestinal part cranial to the obstruction was dark red to cyanotic and mild peristalsis was persisting, hence only enterotomy was done as indicated by Albernaz et al. (2017); while, Crha (2008) suggested enterectomy and anastomosis in cases of necrosis of intestinal loops. Retrieval of various objects indicate the indiscriminate feeding habits of the dogs and diseases like pica which prone the dogs to allotrophagia (Muhammad et al., 2014). The death of the dog may be attributed to delay in presentation, toxaemia and post-surgical stress.

\section{References}

1) Albernaz VGP, Conceição RT, Eising TC, Fabris IA, Mamprim MJ and Rahal SC, 2017. Partial Obstruction of the Small Intestine by a Trichobezoar in a Dog. Acta Scientiae Veterinariae 45(1): 210.

2) Atray M, Raghunath M, Singh T, Saini NS, 2012. Ultrasonographic diagnosis and surgical management of double intestinal intussusception in 3 dogs. Canadian Veterinary Journal 53(8):860.

3) Crha M, Lorenzova J, Urbanova L, Fitchel T and Necas A, 2008. Two Techniques of Intestinal Wall Suture in Surgical Treatment of Ileus in Dogs and the Importance of Omentalisation. Acta Veterinaria Brno 77: 263-267

4) Ellison GW, 1990. Enterotomy. In current techniques in small animal surgery. Editor, M. Joseph Bojrab, $3^{\text {rd }}$ ed., Lea and Febgier, Phildelphia pp: 249.

5) Hayes G, 2009. Gastrointestinal foreign bodies in dogs and cats: a retrospective study of 208 cases. Journal of Small Animal Practice 50: 576 - 583

6) Muhammad ST, Audu SW, Jahun BM, Lawal M Adawa DAY, 2014. Diagnosis and management of sand impaction of the large intestine in an Alsatian puppy. Sokoto Journal of Veterinary Science 12 (2): 57 60

7) Prasad BC, Rajesh MM and Rao CM, 2010. Intestinal obstruction in a dog due to saree piece. Vet. World. 3 (9): $429-430$

10) Raghunath M, Sagar PV, Sailaja B and Kumar PR, 2016. Surgical Correction of Intestinal Obstruction in a German Shepherd Dog. Scholars Journal of Agriculture and Veterinary Sciences 3(3): 187-189

11) Tams T and Seim H, 2013. Gastrointestinal foreign body obstruction in dogs. Paper presented in Western Veterinary Conference, SA290. 